\title{
Antisoiling Technology: Theories of Surface Soiling and Performance of Antisoiling Surface Coatings
}

\author{
E.F. Cuddihy \\ P.B. Willis
}

Novembe: 15.1984

Prepared for

U.S. Department of Energy

Through an Agreement with

National Aeronautıcs and Space Administration

by

Jet Propulsion Laboratory

California Inslitute of Technology

Pasadena. Cahfornia

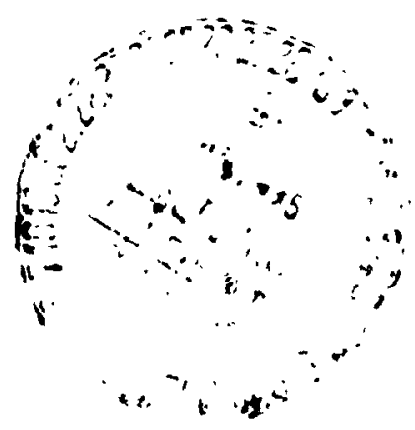

JPL Publication 84.72 


\section{Antisoiling Technology: Theories of Surface Soiling and Performance of Antisoiling Surface Coatings}

E.F. Cuddihy

P.B. Willis ${ }^{\star}$

*Springborn Laboratories, Inc. Enfield, Connecticut

Prepared for

U S Department of Energy

Through an Agreement with

National Aeronautics and Space Administration

by

Jet Propulsion Laboratory

Californa institute of Technology

Pasaderia. Calıforna

IPL Publication 84.72 
Prepared by the Jet Propulsion Laboratory, California Institute of Technology, for the U.S. Department of Energy through an agreement with the National Acronautics and Spece Administration.

The JPL Flat-Plate Solar Array Project is sponsored by the U.S. Department of Energy and is part of the Photovoltaic Energy Systems Program to initiate a major effort toward the development of cost-competitive solar arrays.

This report was prepared as an account of work sponsored by an agency of the United States Government. Neither the United States Government nor any asency thereof, nor any of their employees, makes any warranty, express or implied, or assumes any legal liability or responsibility for the accuracy, completeness, or usefulness of any information, apparatus, product, or process disclosed, or represents that its use would not infringe privately owned rights.

Reference herein to any specific commercial product, process. or service by trade name, trademark, manufacturer, or otherwise, does not necessarily constitute or imply its endorsement, recommendation, or favoring by the United States Government or any aency thereof. The views and opinions of authors expressed herein do not necessarily state or reflect those of the United States Government or any agency thereof.

This publication reports on work done under NASA Task RE-152, Amendment 66, DOE / NASA IAA No. DE-A101-7EET20356. 
Physical examination of surfaces undergoing natural outdoor soiling suggests that soil matter accumulates in up to three distinct layers. The first layer involves strong chemical attachment or strong chemisorption of soil matter on the primary surface. The second layer is physical, consisting of a highly organized arrangement of soil creating a gradation in surface energy from a high associated with the energetic first layer to the lowest possible state on the outer surface of the second layer. The lowest possible surface energy state is dictated by the chemical and physical nature of the regional atmospheric soiling materials. These first two layers are resistant to removal by rain. The third layer constitutes a settling of loose soil matter, accumulating in dry periods and being removed during rainy periods.

Theories and evidence suggest that surfaces that should be naturally resistant to the formation of the first two rain-resistant layers should be hard, smooth, hydrophobic, free of first-period elements, and have the lowest possible surface energy. These characteristics, evolving as requirements for low-soiling surfaces, suggest that surfaces or surface coatings should be of fluorocarbon chemistry.

Evidence for the three-soil-layer concept, and data on the positive performance of candidate fluorocarbon coatings on glass and transparent plastic films after 28 months of outdoor exposure, are presented. 

CONTENTS

I. INTRODUCTION ..................... 1

II. SOILING THEORY ...................... 3

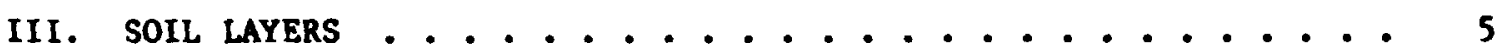

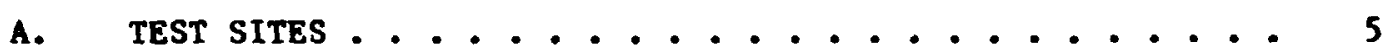

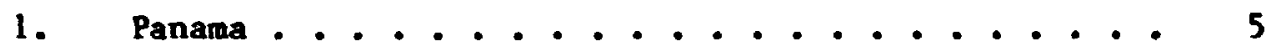

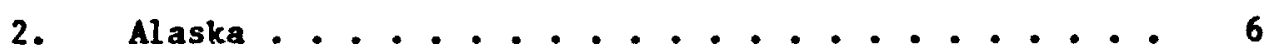

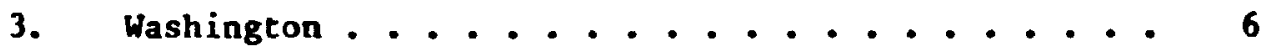

B. TRANSPARENT TAPE SAMPLING ............ 7

c. THREE SOIL LAYERS ................. 8

D. JET PROPULSION LABORATORY SOILING STUDIES ....... 9

E. THEORETICAL SPECULATIONS .............. 15

1. Layer A ..................... 17

2. Layer B ..................... 17

3. Layer C ..................... 19

IV. LOW-SOILING COATINGS ........................... 21

v. SURAARY .......................... 29

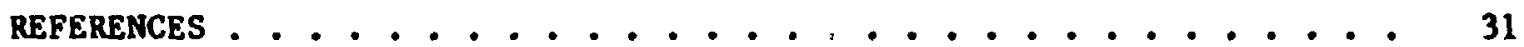

\section{Figures}

1. The Three Soiling Layers .............. 9

2. Behavior of Natural Outdoor Soiling ......... 10

3. General Pattern Observed in JPL Outdoor Soiling Data

for GE RTV-615 Soft Silicone at Point vicente,

Goldstone and Table Mountain, California........ 11 
4. Effect of Tilt Angle on Accumulation of Soil Layer $\mathrm{C}$

(Data From Table 1, JPL Sites) ...............

5. Percentage of Reduction in Solar-Ce11 Short-Circuit

Current From Soiling of Korad 212 Acrylic Film as

a Function of Duration of Exposure at

Pasadena, California ...................

6. Hierarchy of Spontaneously Adsorbed Layers on a

Metal Surface (Adapted From Reference 14) . . . . . . . 16

7. Outdoor Soiling Behavior of Tedlar 100BG30UT

Plastic Film, With and Without a Fluorocarbon

Antisoiling Coating . . . . . . . . . . . . . . . .

8. Outdoor Soiling Behavior of Acrylar X-22417

Plastic Film, With and Without a Fluorocarbon

Antisoiling Coating .................. n

9. Outdoor Soiling Behavior of Glass With and Without

a Fluorocarbon Antisoiling Coating . . . . . . . . . 25

10. Rainfall in Enfield, Connecticut, Over a 28-Month Period . 26

Tables

1. JPL Soiling Data: Reductions in Short-Circuit Current

from Soiling Layers, $\%$. . . . . . . . . . . . . .

2. Experimental Evaluation of Fluorocarbon Antisc iling

Coating, Monitored by Measurements of Percent ge of

Reduction in Solar-Cell Short-Circuit ( $I_{s c}$ ) From

Accumulation of Natural Surface Soiling (Reference 18)..

3. Time-Averaged Values of the 28-Month Soiling

Data Given in Table $2 \ldots . . . . . . . . .$. 


\section{SECTION I}

\section{INTRODUCTION}

The accumulation of dust, dirt, pollen, and other atmospheric contaminants and particles on the surfaces of solar-energy devices such as solar-thermal collectors and photovoltaic (PV) modules results in a loss of performance due to a decrease in transmitted sunlight. This accumulation of a diversity of deposited atmospheric materials, hereafter referred to as soil, reduces light transmission by combined action of absorption and scattering. To minimize performance losses caused by soiling, solar devices should have surfaces or surface coatings that have low soil retention, and maximum susceptibility to natural cleaning by wind, rain and snow, and that are readily cleanable by simple and inexpensive maintenance techniques.

A review of literature published before 1980 (Reference 1) found no information specifically addressing the nature of surface soiling, nor on characteristics of surfaces or surface coatings t' at provide low to zero soil retention, or ready cleanability by natural means. Accordingly, the Flat-Plate Solar Array Project (FSA), managed by Jet Propulsion Laboratory (JPL) for the U.S. Department of Energy (DOE), est iblished a program to investigate surface soiling to establish chemical, physical, and mechanical criteria for low-soiling surfaces or surface coatings.

The soiling program was divided into four activities: (1) measurement, as a function of time, of the decrease in light transmittance resulting from the natural accumulation of soiling on the surfaces of a wide variety of glasses and transparent plastic films mounted on outdoor exposure racks at various geographical locations; (2) chemical and physical analysis of the soiling matter on these surfaces; (3) generation of theories and hypotheses on the chemical and physical requirements of surfaces for luw soil retention, and on the details of the formation and construction of the soil retained on surfaces, and (4) identification and evaluation of candidate low-soiling surface coatings or treatments.

This report has two subjects: (1) an initial effort at describing the details of formation and construction of the natural soil retained on surfaces, and (2) performance of candidate low-soiling surface coatings. 



\section{SECTION II}

SOILING THEORY

Although the search of published literature for information on prevention of surface soiling was not directly fruitful, several articles (References 2-7) were found, which, in combination with experimental light transmittance measurements (References 8,9 ), made possible initial theoretical definitions (Reference 1) of the requirements of low-soiling surfaces or surface coatings, and of the requirements for low-soiling environments. The requirements for low-soiling surfaces appear to be:

(1) Hardness

(2) Smoothness

(3) Hydrophobicity

(4) Low surface energy

(5) Nonstickiness (chemically clean of sticky materials, surface and bulk)

(6) Cleanliness (chemically clean of water-soluble salts and first-period elements, surface and bulk)

and the requirements for low-soiling environments appear to be:

(1) Low to zero airborne organic vapors

(2) Frequent rains, or generally dry (low dew, low RH)

(3) Few dew cycles or occurrences of high RH between heavy rain periods.

Further, of the expected natural cleaning agents--wind, rain, and snow--only rain is really effective. Witl: respect to snow, observations have been made (Reference 10) that the surfaces of photovcltaic modules and mirrors are noticeably quite clean after a heavy snow pack has slid off the tilted modules. The presumption is that cleaning is accomplished by a combination of abrasive action and the presence of 1 iquid water at the module surface/snow pack interface. However, accumulated snow that is removed by melting and not sliding is not effective (Reference 11 ).

Wind is also not an effective cleaning agent. The aerodynamic lifting action of wind can remove particles greater than about $50 \mathrm{~m}$ from surfaces (Reference 4), but is ineffective for smaller particles. Thus, the particle size of soil matter is generally found to be less than $50 \mathrm{~m}$, and predominantly to be less than 5 m (References 12, 13).

In general, rain appears to be the primary natural cleaning agent, but rain is not necessarily effic snt at all times in removing all accumulated 
soil on a surface. Reference 1 describes known and speculated mechanisms of soil adhesion to surfaces. These mechanisms result in resistance to soil removal by rain, and the abovementioned six requirements of low-soiling surfaces are theoretically considered as required to minimize rain-resistant adherence of soil matter on surfaces. Based on these theoretical considerations, candidate low-soiling surface coatings based on fluorocarbon chemistry could be identified. These coating materials and their positive performance after 28 months of outdoor exposure are reported here.

In addition, FSA activities related to the removal of soil specimens from the surfaces of soiled photovoltaic modules, using transparent adhesive tape, for later chemical and physical analysis, in combination with detailed observatiors of the maintenance washing and cleaning of these soiled surfaces, resulted in a theoretical speculation that soil accumulates in tiers of up to three distinct layers. These layers are designated, outward rom the surface, as $A, B$, and $C$. Layer $C$ always forms during dry periods, and is renoved during rainy periods. Layers $A$ and $B$, which are resistant to removal oy rain, may or may not form, but if they do, will be in the sequence $A$ followed by $B$ (followed by $C$ ), or B only (followed by $C$ ). Therefore, refinement of the soiling theory suggests that the six requirements for low-soiling surfaces are those for preventing the formation of layers $A$ and $B$, or $B$ alone, but will have no influence on layer $C$. The observational evidence for the natural formation of up to three soil layers, and an attempt at a chemical and physical description of each of these layers, are reported below. 


\title{
SECTION III
}

\author{
SOIL LAYERS
}

The concept that soiling behaves as though it were accumulating in tiers of up to three distinct layers resulted serendipitously from an effort to lift surface soil from test surfaces with a transparent adhesive tape for analysis. The soil samples were to be taken from the surfaces of photovoltaic modules exposed outdoors at test sites in Panama, Alaska, and Washington. At each site three modules of different designs, with three different surfaces, were accumulating soil. The three surfaces were:

(1) A soft silicone elastomer (GE RTV 615)

(2) A semihard silicone coating (Dow Corning Q1-2577)

(3) Hard soda-lime window glass.

\section{A. TEST SITES}

\section{Panama.}

At the Panama site each of the three surface types was soiled. Hand washing with a solution detergent in water cleaned the glass surfaces thoroughly, but cleaned the soft and semihard silicone surfaces only partially. The residual soil on these silicone surfaces, which could not be removed by hand washing, appeared to constitute a thin, uniform, tan-gray coating over the whole of the module surfaces. This coating could only be removed by vigorous and abrasive scrubbing, which was conveniently performed with a slightly moistened thumb. The scrubbed area, cleaned of the tenacious soil coating, exhibited the crystal-clear, water-white appearance associated with fresh, unsoiled silicone.

The Panama observation suggested the existence of two presuinably distinct layers of soil on the silicone surfaces: a primary layer directly on the silicone surface, very tenacious, which could not be removed by washing, and on top of the primary layer a secondary layer that could readily be removed by washing. The glass surfaces, on the other hand, could be washed clean of all soiling matter. In the interest of establishing definitions, the soil layer on glass was comparabl. to the secondary soil layer on the silicones, in the operational sense what they both could be removed by hand washing. Thus, when observed at Panama, glass was covered with a secondary layer of soil, while the silicones were covered with both a primary and a secondary layer of soil.

Conversations with persons who operate the Panama test site revealed that rain occurs there almost daily over an eight-month pe:-iod from April to November, and almost none at all, or very little, occurs during a dry period from December to March. They noted that more soil can be observed on the modules during the dry period than during the rainy period. When the rains begin in April, some soil is removed. The inspection of the Panama modules 
was done in mid-May, when presumably only rain-resistant soil remained on the module surfaces. However, the observation of additional soil during the dry months suggested the existence of yet a third characteristic surface layer of soil, probably the outermost layer, which is removable by rain. Since this third type of soil layer builds up during dry periods, and is depleted during rainy periods, it probably is a fluctuating surface layer whose quantity of soiling matter fluctuates in some sequence with rain patterns.

\section{Alaska}

At the Alaska site in mid-August it was observed that the glass surfaces were extremely clean, with no visual evidence of any soil on thri $r$ surfaces. The soft and semihard silicones, however, were soiled. Frequent rains in the local area preceded the inspection.

Hand washing did nothing for the glass modules, removed essentially all soil from the semihard silicone, and cleaned the soft silicone surface only partially. The tenaciously adhesive soil layer remaining on the soft silicone surfaces had the same appearance as that observed in Panama, and could be removed by abrasive scrubbing. The scrubbed area became crystal clear. It was also observed that the soft silicone surface was rough, as though it had been sandblasted. This surface roughness was not observed on the semihard silicone or the glass surfaces (nor on any surfaces at Panama or Washington).

In conversations with persons who operate the Alaska test site, it was learned that the local soils are acidic (soils at the Panama site are alkaline), and that they had often observed soil on the glass surfaces, and always on the silicone surfaces.

For the Alaska site, it is observationally inferred that a rain-removable layer settles on all surfaces during dry periods, that a rain-resistant secondary soil layer does not form on glass, that a rain-resistant secondary soil layer forms on the semihard silicone, and that both primary and secondary rain-resistant soil layers form on the soft silicone.

\section{Washington}

At the site in the state of Washington, all module surfaces were observed to be soiled. About two days earlier, the area experienced a heavy and intense thunderstorm. Hand washing cleaned all soil from all of the surfaces. Unlike those in Panama, and the soft silicone at Alaska, all of the silicone surfaces washed clean, and acquired the crystal-clear appearance of fresh silicone.

Accepting the operational definition that a secondary soil layer is rain-resistant but hand-washable, then all of the surfaces at the Washington site had acquired a secondary soil layer, and none of the surfaces had acquired a primary layer. The Washington site is immediately adjacent to the heavily travelled Interstate Highway 5 between Seattle and Tacoma, and within a mile of a plant that converts coal to diesel fuel and road asphalt. The 
secondary soil at this site is a composite of an oily deposit of organic aerosols and vapors, overcoated with soiled particulates.

\section{B. TRANSPARENT TAPE SAMPLING}

At Panama, two modules with soft silicone surfaces (GE RTV 61j) wrre visibly quite dirty, and had never been washed. They had been outdoors for about three years. When transparent adhesive tape was placed on the dirty surface of one of the modules for soiling sampling, two observations were made: the tape piece readily and immediately adhered to the soiled surface, and visibility through the tape into the silicone interior was strikingly improved over visibility of the silicone interior when viewed through the untaped soiled surface. The enhanced clarity of the taped area $d$ tifuded $\hat{c}$ dramatically clearer and sharper view of the underlying sola- se $^{\text {: }}$ and substrate panel, as compared with the obscurity of the untaped surface.

However, the taped area did not acquire the crvstal-c.ear appearatics associated with a clean, brand-new soft silicone sirface; t'sere was a : an-grey color under the tape, which appeared to be uniform over the entire tapec area.

When the tape was peeled off the surface, some soil adhered to the tape, but in the tape-sampled area, the thin, uniform, tan-grey soil coating remained. This coating was virtually identical in appearance with the tenaciously adhering coating that could not be removed by hand washing. The residual coating in the tape-sampled area could be removed by abrasive scrubbing, exposing the crystal-clean appearance associated with a clean silicone surface.

At Panama, the tape overlay acted optically to eliminate or reduce the light obscuration associated with the secondary soiling laye:. The tape alsr caused optical disappearance of the secondary soiling layer; thus, the next lower layer was revealed through the tape, which for these modules was the tenaciously adhering, tan-grey primary soil layer.

At Washington, tape overlays on the unwashed modules were startling, affording crystal-clear views into the interiors of the modules. Since subsequent washing revealed that these modules, particularly the silicone modules, were free of tenaciously adhering primary soil layers, the speculation derived at Panama, namely that the tape reveals the next lower layer, became increasingly supported, since the next lower layer for the modules are the crystal-clear surfaces of the silicone or glass.

Putting tape overlays onto the unwashed surfaces of the Washington modules presented a problem. The tape would not adhere readily to the soiled surfaces. The procedure was to lay one edge of the tape $0_{1}$ the surface, positioned under a thumb, then to slide the thumb asong the tape, from end to end. Thumb pressure is intended to be gentle. As the thumb moved along tive tape surface, the tape in the wake of tr, thumb lifted from the surface. Excessive thumb pressure and several repetitive rubs were requi.ed to achieve a nondelaminating contact. This nonstick behavior of the tape strongly supported the conclusion that the surface soiling matter was probably dominated by oily chemicali. This conclusion was reached in view of the 
area' $\varepsilon$ potential for oily materials originating at both the highway and the nearby plant, and the intuitive expectation that an adhesive tape should not stick reatily to an oily sur ace (the presence of an oily film on the silicone surfaces can be credited with inhibiting the formation at this site of the tenaciously adhering primary soil layer).

The "Hide-a-Layer, Reveal-the-Next" effect of the tape overlay was also observed at the Alaska site. A tape overlay on the unwashed soft silicone modules revealed the tan-grey primary soil layer, and after the modules were washed, a tape overlay on the primary soil layer offered a crystal-clear view into the interior of the module. A tape overlay on the unwashed semihard silicone modules resulted in a crystal-clear effect, and these modules, when washed, were observed to be free of a primary soil layer.

\section{THREE SOIL LAYERS}

The three soil layers whose existence was indicated from field observations are illustrateu in Figure 1. They can be designated and defined for descriptive convenience as follows:

(1) Layer A, a primary surface layer of soil that is resiscant to removal by rain, washing, and adhesive tape. This layer can only be removed by abrasive scrubbing.

(2) Layer B, a secondary surface layer of soil that is resistant to removal by rain, but can be readily removed by washing or adhesive tape.

(3) Layer C, a tcp surface layer of dirt that can be readily removed by rain. The depth of layer $C$ fluctuates with rain patterns.

The field observations suggest that if layer A forms, it will do so directly on the material surface, and then layor $A$ will be overcoated with layer $B$, which in tirn will be overcoated with layer $C$.

If layer A d. s not form, then layer $B$ will form directly on the morial surface, and then will be overcoated with layer $C$.

If layer $B$ does not form, then only layer $C$ will resif on the material surface. The field observations did not indicate in any way that layer $C$ will reside directly on layer $A$, without the intermediary layer $B$.

In other words, the soiling possibilities seem to be:
(1) $\mathbf{A}+\mathbf{B}+\mathbf{C}$
(2) $B+C$
(3) C only 


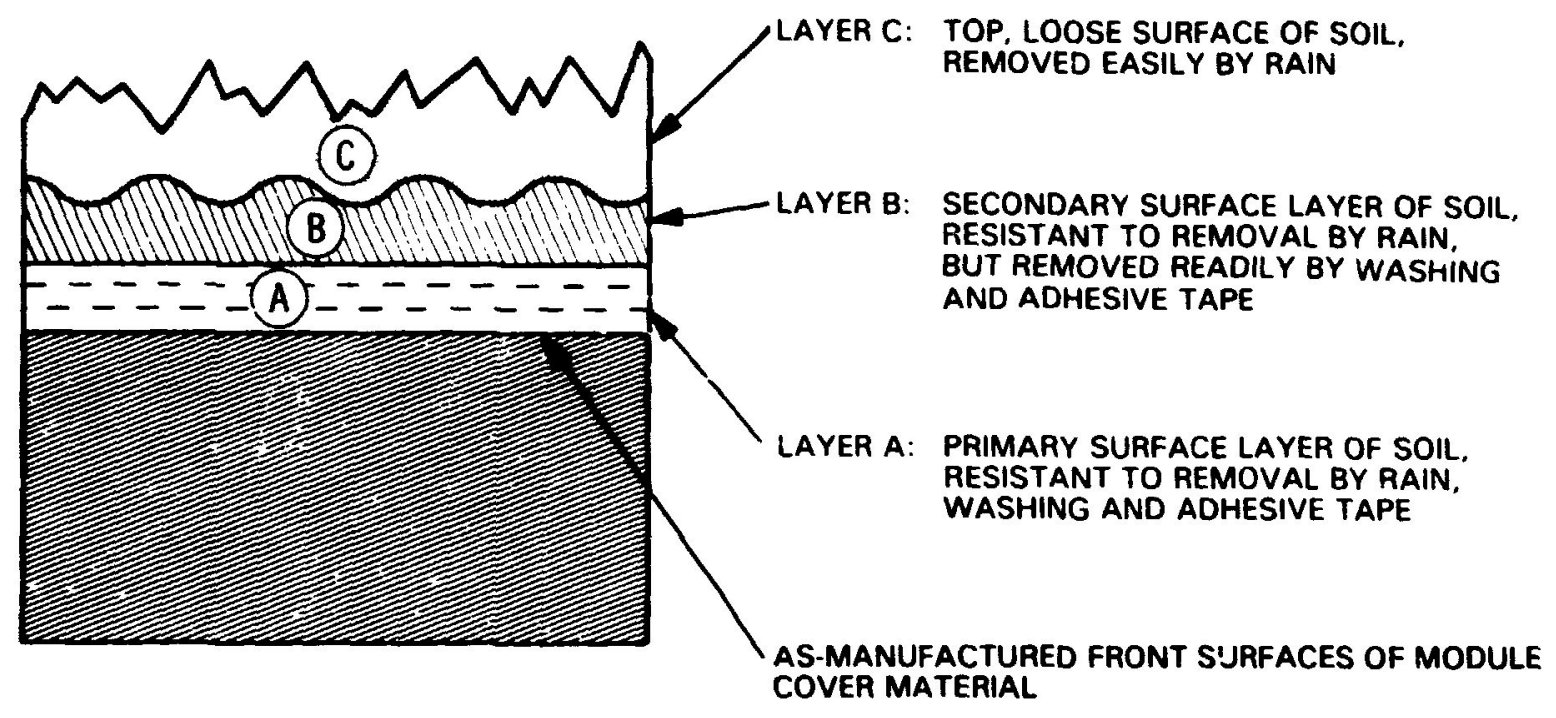

Figure 1. The Three Soiling Layers

\section{JET PROPULSION LABORATORY SOILING STUDIES}

Before speculating on chemical and physical principles of soii layer formation, pertinent results from measurement of the decrease in light transmittance of seven different transparent materials being soiled naturally at 11 climatically different locations are described (References 8, 9). The seven materials include three different glasses: an aluminosilicate glass, a borosilicate glass, and a soda lime glass; and four polymers, Korad acrylic film, Tedlar fluorccarbon film, the semihard silicone surfacing material, and the soft silicone elastomer (RTV-615). The method of measuring soiling accumulation involves the measurement of the short-circuit current from a standard solar cell positioned behind the transparent materials.

The short-circuit current of a solar cell is directly proportional to light transmittance, and decreases with increasing quantities of soil on the surfaces of the transparent material. Test results are reported as a percentage, using the equation

$$
\text { Loss from soiling, } \%=\frac{I_{c}-I_{s}}{I_{c}} \times 100
$$

where $I_{c}$ is the short-circuit current measured with the clean transparent material over the cell and $I_{s}$ is the short-circuit current measured with the soiled transparent material over the cell.

The test materials had been outdoors for more than two years, unwashed, and with soiling measurements made on these materials at intervals of two to three months. The time-dependence of the outdoor soiling behavior of the materials generally follows the pattern schematically illustrated in Figure 2. The oscillating solid line traces the time-dependent magnitude and 


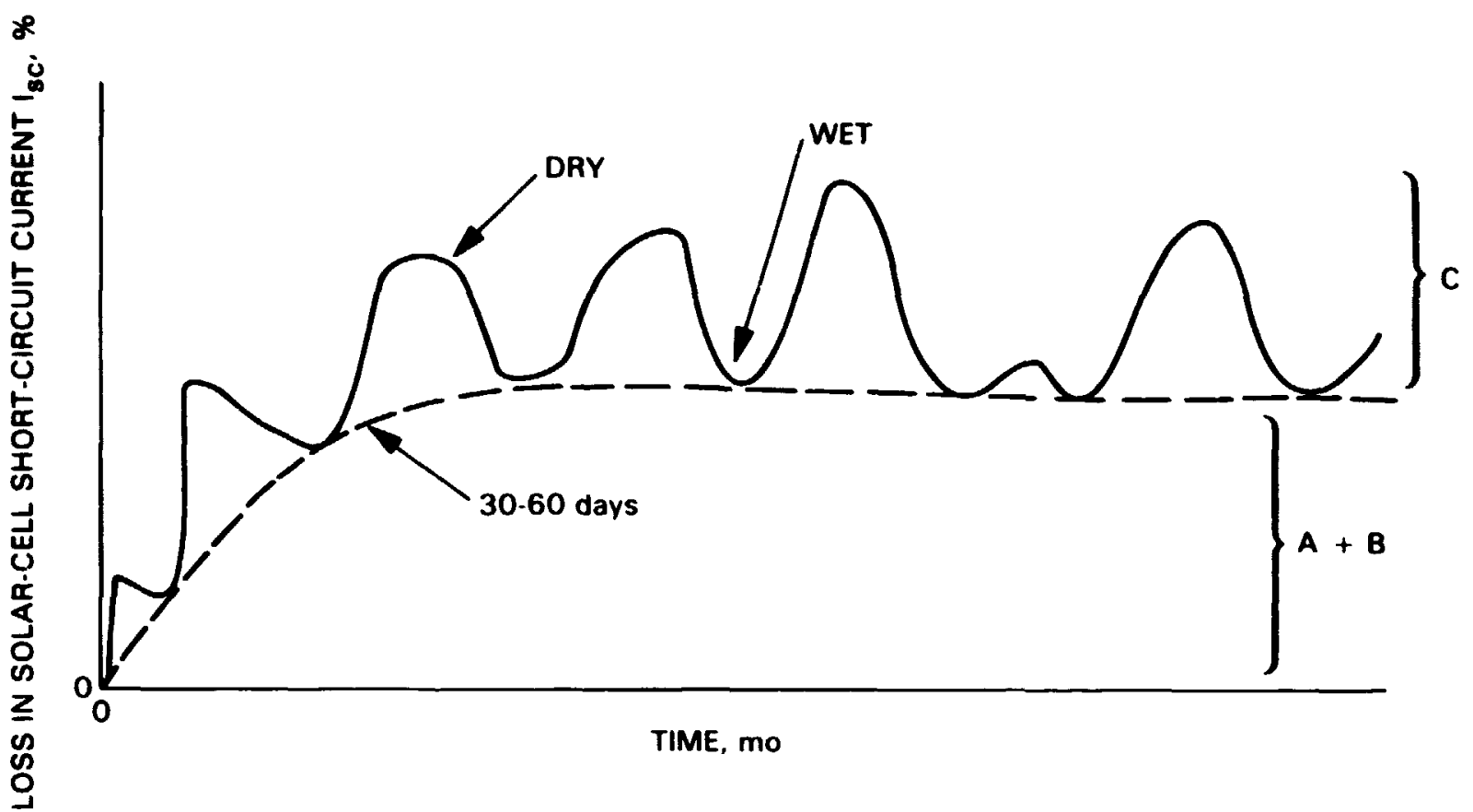

Figure 2. Behavior of Natural Outdoor Soiling

behavior of the surface soiling, which increases during dry periods and decreases during rainy periods.

Accepting the soil-layering concept, the curve in Figure 2 should reflect the existence of rain-resistant and rain-removable soil layers. The dotted line connecting the minimums, therefore, is associated with the light obscuration caused by the development of the rain-resistant layers, either layers $A$ and $B$, or layer $B$ alone, and the solid, oscillating line riding on the dotted line, therefore, is associated with the light obscuration caused by the rain-controlled layer $C$.

With the exception of the soft silicone elastomer (GE RVT-615) at three sites, a general characteristic illustrated in Figure 2 is that the dotted line associated with $A$ and/or $B$ formation rises rapidly for the first 30 to 60 days, and thereafter slows dramatically, ranging for various combinations of materials and sites from a virtual asymptote to a perceptably detectable slope. For the soft silicone at Point vicente, Goldstone, and Table Mountain, however, the dotted line continued to increase as schematically illustrated in Figure 3, and appeared to obey a semilogarithmetic relationship.

An exercise can be done in the region of the JPL soiling data after 30 to 60 days (Reference 9), where the minima of the curves are associated with the light obscuration caused by rain-resistant layers ( $A+B$, or $B$ only), and the difference between this minimum and the maximum observed peak is associated with the maximum light obscuration caused by layer $C$. The latter calculation is arbitrary, as there are other intermediate highs in the soiling data. Thus, the calculated value to be allocated "o layer $c$ represents the maximum quantity of layer $C$ soil to have been present on the surface during the outdoor exposure period. 


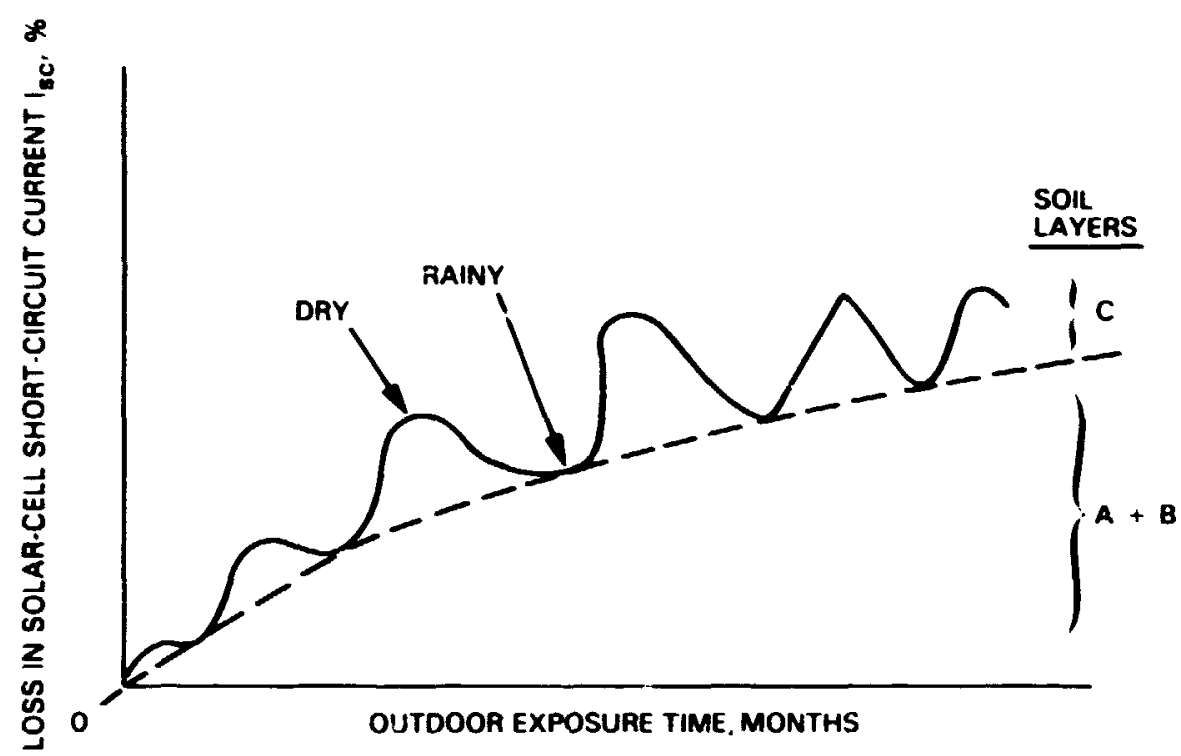

Figure 3. General Pattern Observed in JPL Outdoor Soiling Data for GE RTV-615 Soft Silicone at Point Vicente, Goldstone and Table Mountain, California

Light obscuration values are described in Table 1 using the JPL soiling data (Reference 9) for seven different sites. The available data do not permit decoupling of the minimum into separate values for $A$ and $B$; therefore, the minimum is considered the sum of $A$ and $B$, as indicated in the column heading of Table 1 .

As expected, the data indicate that the largest quantity of rain-resistant soil (Column $A+B$ ) is found on the soft silicone, followed next by the semihard silicone, and last, by the remaining five harder materials. Although the numbers for these five materials are small, there is an indicated ranking. Comparing the plastic films, the fluorocarbon (Tedlar) is slightly better than the acrylic (Korad). Comparing the glasses, the ranking (in improving order) is soda-lime, aluminosiliate, and borosilicate. As was observed for glass at Alaska, the JPL soiling data indicate for some combinations of sites and materials that neither layer $A$ nor layer $B$ has formed (the minima of the soiling curves are zero). The data suggest that the formation of the rain-resistant soil layers are both material- and site-dependent, but that material dependency dominates. The trend of surface properties for minimizing the formation of $A$ and $B$ layers, as revealed in Table 1, supports the concept of the theoretically derived six requirements of low-soiling surfaces as described above, in the retion on soil theory.

There is a strong indication in the data that the magnitude of layer $C$ soiling is site-dependent and material-independent. This is understandable; given the development of layer B, it is on this surface, rather than the natural-material surface, that layer $C$ resides. Thus, the development of layer $B$ leads to material independence. For those materials that do not form a layer $B$, their natural surface must have properties similar to those of layer B. 
Table 1. JPL Soiling Data: Reductions in Short-Clrcuit current from Solling Layers, $\%^{a}$

\begin{tabular}{|c|c|c|c|c|c|c|c|c|c|c|c|c|c|c|}
\hline Site & Torran & & $\begin{array}{c}\text { Point } \\
\text { Vicente }\end{array}$ & & Goldet & one & $\begin{array}{c}\text { Teble } \\
\text { Mountain }\end{array}$ & & Pacade & $n a^{b}$ & $\begin{array}{l}\text { JPL } 34- \\
\text { Bite }\end{array}$ & $e^{-d e s}$ & $\begin{array}{l}\text { JPL } 45 \\
\text { Site }\end{array}$ & des \\
\hline \multirow{2}{*}{ Materials } & $A+B$ & c & $A+B$ & c & $A+B$ & c & $A+B$ & c & $A+B$ & c & $A+B$ & c & $A+B$ & $\mathbf{c}$ \\
\hline & \multicolumn{10}{|c|}{ Reduction, $x$} & & & & \\
\hline $\begin{array}{l}\text { Soft Silicone } \\
\text { RTV } 615\end{array}$ & 20 & 10 & $?$ & $?$ & $?$ & $?$ & $?$ & $?$ & 25 & 8 & 24 & 6 & 24 & 7 \\
\hline $\begin{array}{l}\text { Semihard } \\
\text { Silicone, } \\
\text { Q1-2577 }\end{array}$ & 14 & 8 & 3 & 2 & 6 & 2 & 1 & 3 & 17 & 15 & 16 & 12 & 15 & 8 \\
\hline $\begin{array}{l}\text { Acrylic film, } \\
\text { Korad } 212\end{array}$ & 3 & 8 & 0 & 8 & 1 & 2 & 2 & 1 & 5 & 14 & 3 & 13 & 3 & 11 \\
\hline $\begin{array}{l}\text { Fluorocarbon } \\
\text { Film, Tedlar }\end{array}$ & 1 & 8 & 0 & 5 & 0 & 2 & 0 & 2 & 3 & 13 & 1 & 16 & 2 & 12 \\
\hline Soda-Lime Glass & 2 & 6 & 1 & 4 & 2 & 2 & 0 & 2 & 3 & 9 & 4 & 12 & 3 & 9 \\
\hline $\begin{array}{l}\text { Aluminosilicate } \\
\text { Glass }\end{array}$ & 1 & 12 & 1 & 3 & 0 & 2 & 0 & 2 & 2 & 12 & 2 & 13 & 2 & 11 \\
\hline $\begin{array}{l}\text { Borosilicate } \\
\text { Glass }\end{array}$ & 0 & 7 & 0 & 5 & 0 & 2 & 0 & 2 & 1 & 11 & 1 & 15 & 1 & 13 \\
\hline $\begin{array}{l}\text { Average for } \\
\text { Layer C }\end{array}$ & & 4.8 & & 4.8 & & 2 & & 2 & & 12.3 & & 3.5 & & 10.6 \\
\hline
\end{tabular}

abata From Reference 9.

bPasadena station of South Coast Air Quslity Management Dietrict.

c 34 deg and 45 deg tilt angles from ground. 
The site dependency of layer $\mathrm{C}$ relates to the atmospheric concentrations of soiling aterials, their types, and rain cycles. The average of the six or seven values of light obscuration by layer $C$ is also included in Table 1 . If the average value for layer $C$ is treated as a measure of the soiling characteristics of an environment, then (of the sites listed in Table 1) JPL. and Pasadena are the dirtiest, and Goldstone and Table Hountain are the cleanest.

The two JPL sites designated as 34 deg and 45 deg are at the same location, differing only in the angles at which test nodules are tilted from the ground. The tilt-angle dependence inplied for layer $C$ is a reduction in layer $C$ accumlation with increasing tilt toward the vertical. Figure 4 is a linear plot of tilt-angle data for layer $C$. Although there are only two data points, it is interesting to observe that a linear extrapolation would suggest no layer $C$ deposition at near vertical alignment. There appears to be no tilt-angle $\in$ ffect on the formation of rain-resistant soil layers $A$ and $B$.

Experimental prograns related to soiling generally consider the development of laboratory techniques to acquire soiled surfaces for study. Since the JPL soiling data indicate that it takes about 30 to 60 days for

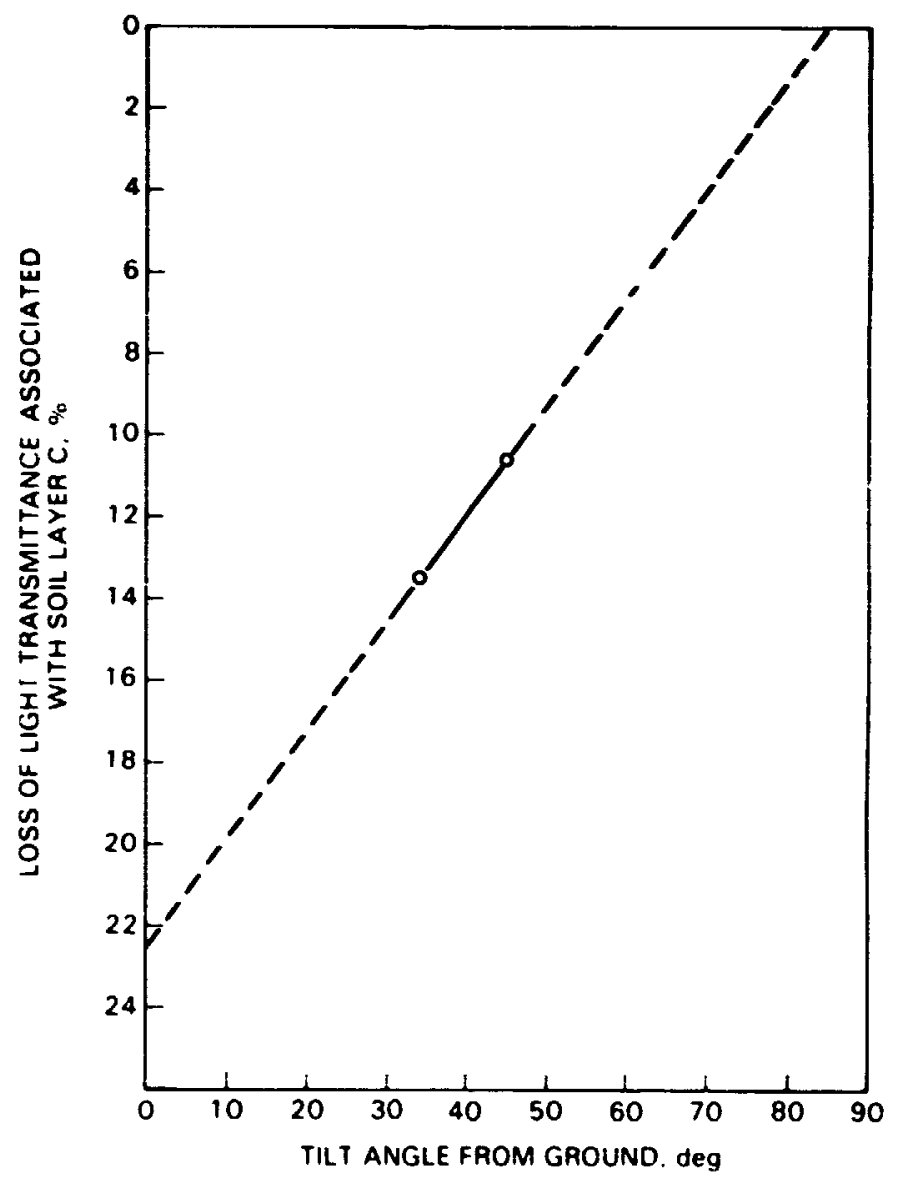

Figure 4. Effect of Tilt Angle on Accumulation of Soil Layer $C$ (Data From Table 1, JPL Sites) 
rain-resistant soil layers to fora, it can be suggested that outdoor exposure at a site where layers $A$ and $B$ will form might be preferred experimentally to laboratory techniques of soil simulation.

The indicated characteristics of the soiling layers suggest for the laboratory that an "onion-skin" approach to peeling away each of the layers could be perforned. Layer $C$ could be rinsed off with water, layer $B$ could be taken off with adhesive tape, and layer $A$ rewoved by scrubbing. With the sequential renoval of each layer, chemical and particle-size analysis of the mitter in each layer could be perfored. ight transmittance losses associated with each layer could be neasured, and otier chemical, physical and optical testing could be done.

Figure 5 is a plot of JPL soiling data for Rorad 212 acrylic film, for one year of outdoor exposure at Pasadena. Each letter in Figure 5 identifies a Rorad film sample that was removed from the outdoor exposure racks on the indicated dates for laboratory light transmittance measurements. No rainfall of any significance occurred from $5 / 1 / 79$ to $9 / 28 / 79$, whereas from $9 / 28 / 79$ to $5 / 12 / 80$, extensive and frequent rainfall occurred in the Pasadena area. Consequently, over this one-year period sample 0 acquired the maximum quantity of accumulated soil, and with the start of the winter rains, layer $C$ was rewoved and the rain-resistant base layers of $A$ and $B$, or $B$ only, remained on samples $P$ through $T$. The percentage of loss in light transmittance through sample 0 acounted to 197 which, based on this data plot, divided as 147 for layer $C$ and $5 \%$ for the rain-resistant base layers.

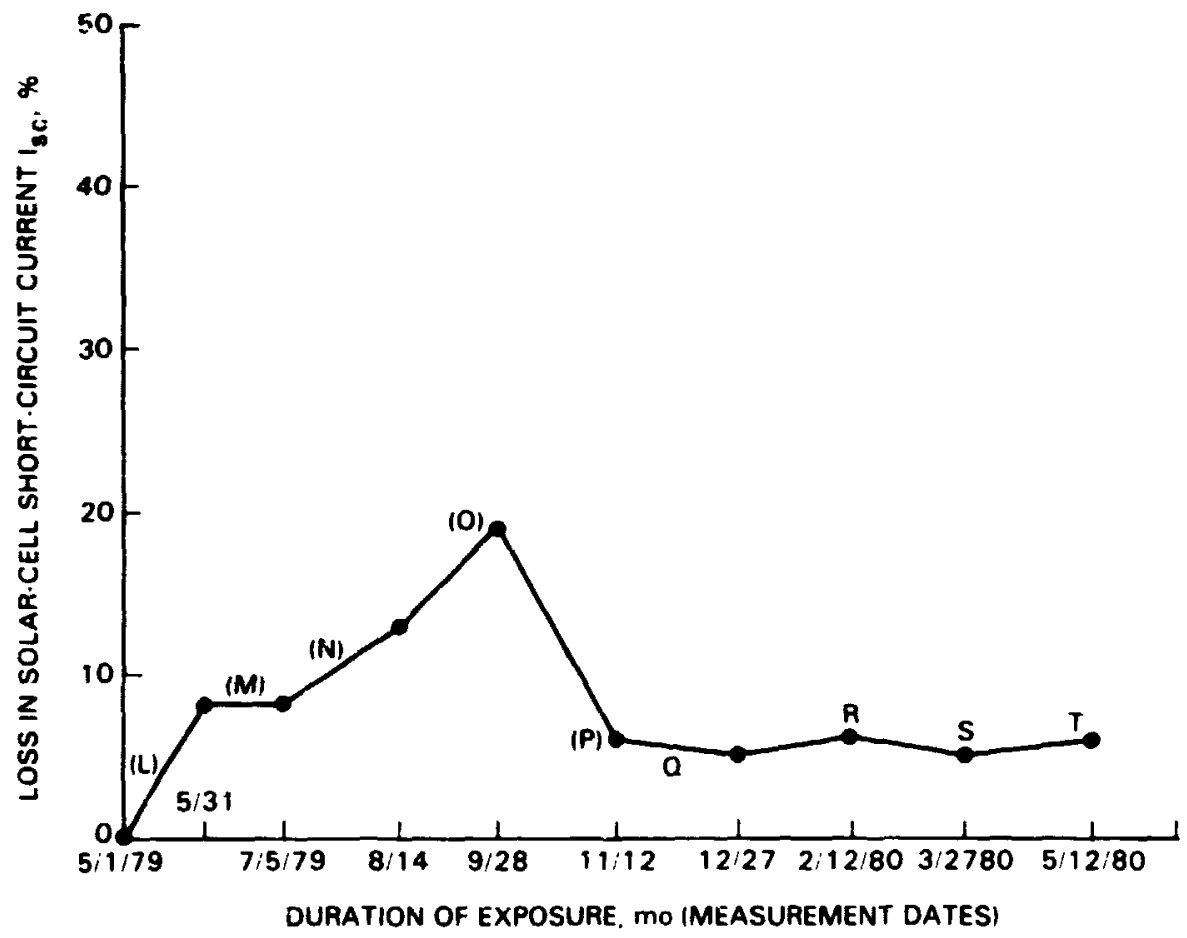

Figure 5. Percentage of Reduction in Solar-Cell Short-Circuit Current From Soiling of Rorad 212 Acrylic Film as a Function of Duration of Exposure at Pasadena, California 
In a simple laboratory test (Reference 13), sample 0 was soaked in a gently agitated liquid water bath for 24 hours, then was allowed to dry in air. Its light transmittance was then reneasured and observed to match that of samples $P$ through $T$. The water soaking simulated rain and effectively removed layer $C$. Next, as a curiosity experiment, sample 0 was soaked in hexane for 30 minutes, which resulted in no change in 1 ight transmission. Whatever remained on sample 0 as soil in the rain-resistant base layer(s) was not affected by hexane.

Last, a piece of transparent adhesive tape was affixed onto that surface of sample 0 bearing the rain-resistant layer of soil, followed by measurement of light transmittance through this composite of two films. The light transmittance increased, essentially to match that of a clean piece of Korad film. This suggested that the primary mechanism for the reduction of $1 \mathrm{ight}$ transmittance associated with the rain-resistant base soil layer(s) on sample 0 is back-scattering rather than light absorption. Finally, the tape was peeled off, with the visual observation that additional soil was removed from sample 0 , and light transmittance through sample 0 now essentially matched that of a clean piece of Korad film. No evidence for a layer $A$ on this Korad film sample 0 could be deduced conclusively. Nevertheless, the concept of the experimental technique for peeling away the separate soil layers was demonstrated in this test.

From the perspective of developing maintenance-cleaning strategies and techniques, the soiling studies suggest that for hard surfaces, light obscuration by rain-resistant layers $A$ and $B$ is low, typically much less than 47. The real problem is the three layers that develop on soft and semihard surfaces, and layer $C$ on hard surfaces. Because soft and semihard surfaces are not favored for solar devices, requirements for establishing maintenancecleaning methods should probably be related to layer $C$ behavior on hard surfaces.

It is being suggested that maintenance cleaning techniques for hard surfaces should not be designed for layers $A$ and $B$, which generate tive least light obscuration but which would require the most demanding cleaning approaches, such as extremely high-pressure water. Rather, cleaning strategies should be developed for layer $C$, perhaps a low-pressure water spray (rain simulation) during dry cycles.

The economics of field-cleaning strategies should be a tradeoff between performance losses by the $A$ and $B$ layers, the $C$ layer, and their respective cleaning costs with respect to the $A$ and $B$ layers. The JPL soiling studies suggest that $A$ and $B$ layers would form again within 30 to 60 days after cleaning.

\section{E. THEORETICAL SPECULATIONS}

This subsection speculates on chemical and physical principles that may be involved in the development and formation of rain-resistant soil layers $A$ and $B$. The principles to be initially considered are those that have been identified for absorbed layers of atmospheric gases on metallic surfaces as illustrated in Figure 6, adapted from Reference 14. The assumption to be made 


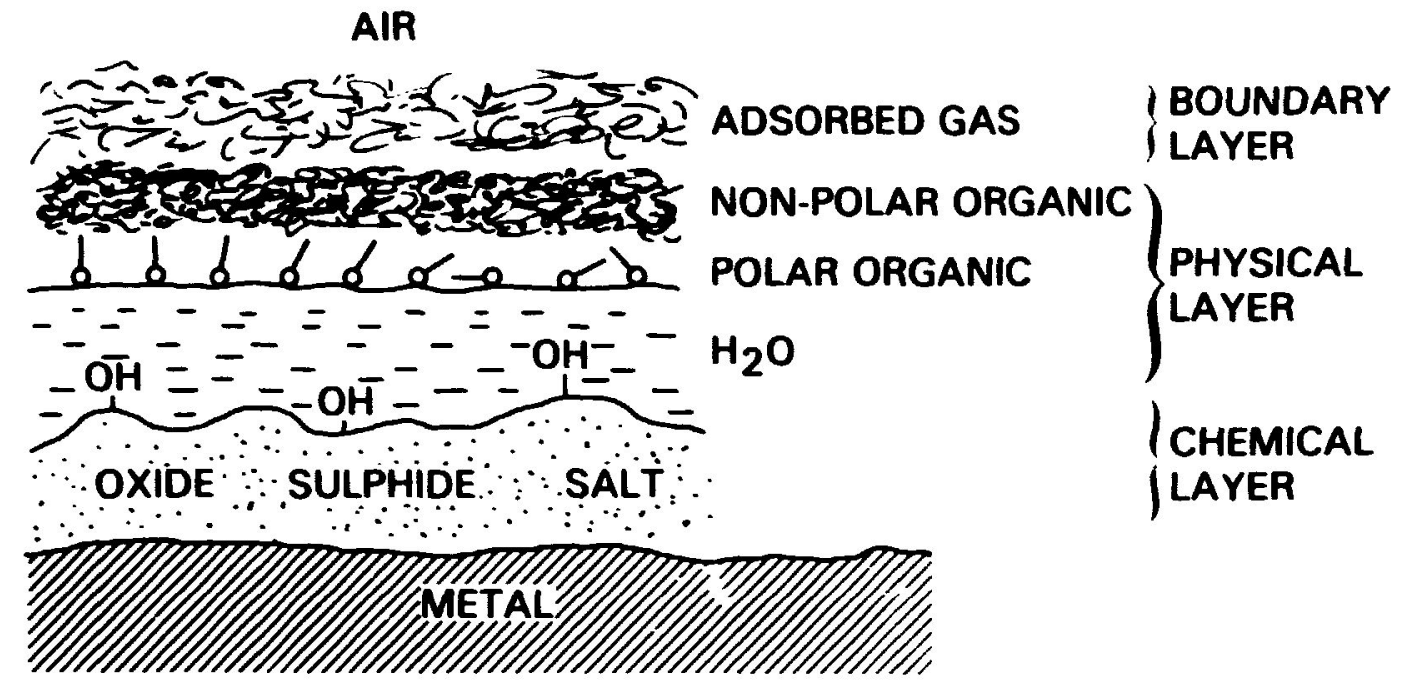

Figure 6. Hiers:chy of Spontaneously Adsorbed Layers on a Metal Surface (Adapted From Reference 14)

is that the principles involved in the accumulation of absorbed layers of atmospheric gas molecules on surfaces apply equally to the accumulation of atmospheris soil particles.

The absorption of atmospheric gases on metallic surfaces appears to involve three distinct layers, as follows:

(1) The chemical layer: a layer of chemical reaction products formed on the metal surface with reactive atmospheric gases such as oxygen, water, hydrogen, $\mathrm{SO}_{\mathrm{x}}$, etc. When $\mathrm{all}$ of the chemically reactive metal surface has reacted, the chemical layer stops growing. The chemical layer adheres tenaciously to the metal surface.

(2) The physical layer: Inasmuch as the surface of the chemical layer has a high surface energy, strong physical absorption of atmospheric gases will occur on this surface. The physical layer so initiated grows outward in such a way that a transition from the high surface energy of the chemical layer to a lower surface energy occurs. In essence, the physically absorbed layer is constructed with a gradient composition of atmospheric gases, progressing from the most energetic at the interface with the chemical layer to the least energetic at the opposite outer surface. The composition of the outer surface of the physical layer consists essentially of those atmospheric gases in the local environment that are the least energetic. When the lowest energy surface state is reached, the physical layer stops growing.

(3) The last layer: essentially a boundary layer of atmospheric gases, with a transitional composition bridging between the physical layer and the ambient atmosphere. The last layer has negligible, if any, adhesion to the physical layer. 
Relating gas-layer accumulation to soil-layer accumulation leads to the following considerations:

\author{
1. Layer $\mathbf{A}$ \\ Two nptions for a tenaciously adhering soil layer can be
}

postulated:

(1) Chemical reaction between soil materials and chemically reactive sites on the surface.

(2) Strong physical adhesion of soil particles to a sticky surface. Additionally, the surface of a material outdoors can be weather-stable, or undergo weathering deterioration, which could increase the chemical reactivity of the surface and/or increase the stickiness of the surface. Layer $A$, and its associated light obscuration, therefore would be expected to stabilize on a weather-stable surface, or to change in accordance with the weathering changes in the surface.

For example, studies of the outdoor weathering of soft silicone elastomers have shown (Reference 15) that the silicone surface will undergo slow UV photooxidation, with associated uptak of water. The surface not only becomes more polar, but also becomes enriched in chemical groups that could react with atmospheric soils. Figure 3 is an illustrative plot of the JPL-monitored soiling behavior of RTV-615 soft silicone at some sites. The dotted line, identified with the development of the $A$ and $B$ layers, was observed to increase continuously at some slow rate, rather than approach an asymptote as observed for the other materials (Figure 2). It is speculated that the continuous increase in the $A$ and $B$ layers results from the weathering of the soft silicone surface. For Point Vicente (Reference 15), the measured first-order reaction rate constant for the surface weathering reaction was in the order of $2 \times 10^{-4}$ day $^{-1}$, and first-order reaction rate constant extracted from JPL soiling data is in the order of $6 \times 10^{-4}$ day $^{-1}$.

In general, a chemically inactive, nonsticky, and weather-stable surface would not be expected to acquire a layer $A$.

\title{
2. Layer B
}

A layer of soil that physically adheres to the surface of layer $A$ or in the absence of layer $A$, to the natural surface of material; as does its gas layer counterpart, it effects a transition from high surface energy to low surface entrgy. Since the energetics of particles decreases with increasing particle-size, layer $B$ is expected to have a gradient in particle-size distribution, increasing from its inner surface to its outer surface. The maximum particle sizes to be found at the outer surface of layer $B$ are expected to be those that would just resist 1 ift-off by wind forces. In addition, particle energetics would be expected also to be dictated by the chemistry of the particle, and in general, it would be expected that organic 
particles would be less anergetic then inorganic particles of the same size. Thus, layer B may have both a particle-size gradient and a chemical gradient, both established by the criterion of a progressive outward decrease in particle energetics.

It is envisioned that the particles in layer $B$ are spatially fixed by being incorporated in a binder of water-soluble salts that have been deposited as soil on the surfaces. This is referred to as cementation (References 1, 2, and 5). At high enough relative humidities, or if the surfaces are covered with dew, the salt solution provides a fluid phase that facilitates the sedimentation of fine particles toward the inner surface of layer $B$. When the water evaporates from the surface, the salt precipitates out of solution and binds the water-insoluble particles.

As layer $B$ is assigned the property of accomplishing an outward transition from high surface energy to a lower surface energy, then the thickness of layer $B$ may be related to the surface-energy difference that must be bridged. Accepting this, several working considerations can be formulated:

(1) If weathering increases the surface energy of the material, then the thickness, and therefore light obscuration, of layer B may increase proportionately. It was noted above that weathering increases the polarity of soft silicone surfaces, which is also an increase in surface energy. Thus it can be speculated that the continued increase in the dotted line of Figure 3 for the silicone results from a continuous building of both layer $A$ and layer $B$. Layer $A$ continues to build because of the increase in chemical reactivity of the surface, and layer $B$ because of the associated increase in surface energy.

(2) If the surface energy of the natural material surface is less than that which would be formed on the surface of a $B$ layer using local soiling materials, then no B layer will form. But a layer B must also physically adhere to an $A$ layer or to the natural surface. It has been shown experimentally that the adhesion strength of clays to window glass is a function of the $\mathrm{pH}$ of the wet clay slurry (Reference 16). Adhesion is low for acid $\mathrm{pH}$, and adhesion increases rapidly as $\mathrm{pH}$ increases into the alkaline region. The soil at the Alaska site is acidic, and thus sufficient adhesion strength to glass to support layer B may not develop, even though it may happen that the glass has a high surface energy. It should also be pointed out that acidic media can etch soft silicone chemically, which may be the origin of the surface pitting observed at Alaska, rather than sandblasting.

(3) 0ils, hydrocarbons, and organics as aerosols and vapors are low-surface-tension contaminants, and as such, if they are in the local environment, are almost always expected to deposit as a thin oily film on surfaces. The resultant oily surface will then be a vehicle for retaining an adherent 
crust of particulates, which may in turn organize to yield a low-energy outer surface for subsequent layer $C$ deposition. The soiling matter at the Washington site was an oily film overcoated with a crust of soiled particulates. The absence of layer $A$ on the soft silicone at the Washington site is thought to be caused by a sealing action of the oily film, which restricts or slows surface weathering.

3. Layer $\mathrm{C}$

After layers $A$ and/or $B$ have formed, using local soiling materials for their construction, a new top surface is formed that is both chemically inert and at the lowest possible surface energy. Thereafter, there is apparently no additional demand of either a chemical or physical nature to retain additional soil that continuously and naturally settles onto the surface for layers $A$ and/or $B$; thus this unneeded soil is removed during rainy periods. Of course, $B$ and/or $A$ need not form if the natural surface has the requisite chemical inertness and low surface energy, but layer $C$ will still form during dry periods, and be removed during rainy periods.

The particle size distribution in laver $\mathrm{C}$ will probably be less than $50 \mu \mathrm{m}$, as particles larger than $50 \mu \mathrm{m}$ are easily removed by wind forces. Layer $C$ will fluctuate in quantity with rain patterns. 

SECTION IV

LOW-SOILING COATINGS

Field soiling observations and JPL soiling data indicate that there are two distinct soiling problems to be dealt with to achieve low soiling. The first is to have top surfaces that resist the formation of the rain-resistant soil layers; the second is related to the rain-removable layer.

As mentioned in Section $I$, there are six characteristics of low-soiling surfaces, postulated in Reference 1:

(1) Hardness

(2) Smoothness

(3) Hydrophobicity

(4) Low surface energy

(5) Nonstickiness (chemically clean of sticky materials, surface and bulk)

(6) Cleanliness (chemically clean of water-soluble salts and tirst-period elements, surface and bulk)

To this 1 ist must now be added a seventh postulate: weather stablity, or alternatively, resistance to UV photooxidation and/or hydrolysis. These seven postulates relate to surface requirements for resisting the formation of rain-resistant soil iayers, and taken in total, lead to the conclusion that the top surface must be a hard, smooth, fluorocarbon material, or a very thin (micrometers) coating of a fluorocarbon on a hard, smooth backing (i.e., 8lass). It would seem reasonable that cost-effective fluorocarbon coatings may be applied to solar-module surfaces to achieve low maintenance costs and to preserve the effective generation of power from these devices.

Candidate materials for the outer surfaces of photovoltaic modules currently consist of low-iron glass, Tedlar fluorocarbon film (Du Po.tt Co. 100BG3OUT) and a biaxially oriented acrylic film, Acrylar (3M Corp. $\mathrm{x}-22417$ ) (Reference 17). These materials are all relatively hard, smooth, and free of water-soluble residues. Experiments were conducted to determine if an improvement in soiling resistance could be obtained by the application of low surface-energy treatments. A survey (Reference 11) of coating materials showed that very few comercial materials exist that could be useful for this purpose. Nevertheless, two candidate fluorocarbon coating materials were identified:

(1) L-1668, an exper; ontal fluorochemical silane produced by $3 M$ Corp. that is used to impart water and oil repellency to glass surfaces. This material will bond chemically to glass surfaces.

(2) Dow Corning Corp. E-3820-103B, an experimental treatment consisting of perfluorodecanoic acid chemically reacted with a Dow 
Corning silane, 2-6020. This compound, which is not commercially available, will bond chemically to glass surfaces.

In a trial test, each of these two fluorocarbon coatings, which are supf 'ied in solvent solutions, were brushed onto the surfaces of the three outer-su-face candidate materials, and allowed to dry in air and react chemically for 24 hours. The treated materials were then soaked in water, simulating rain, to determine if they were adequately attached chemically. The criterion for judging this attachment was whether water would bead up, or wet and spread on the surfaces when the materials were periodically removed from the water bath. By this criterion, both coatings wer: judget to have become permanently attached to glass, the E-3820 to have become attached to the Tedlar, and the L-1668 to have become attached to the Acrylar. Droflets of liquid water on the Tedlar treated with L-1668, and on the lisylar treated with E-3820, tended to wet and spread.

To promote chemical attachment of the L-1668 on $\mathrm{T}$. on Acrylar, the surfaces of both of these films were firs exposure to ozone, to generate surface polar groups that , ... react chemically with the silanes, followed by brushing on the fluorocarbon coating solutions. This technique worked excellently. Therefore, as an additional experiment effort, E-3820 was also applied to an ozone-treated Tedlar surface, and L-1668 was also applied to an ozone-treated Acrylar surface, even though the earlier trial testing did not indicate such a need. The concept was that the ozone treatment may also enhance the adhesion of these fluorocarbon coatings on the plastic films. Glass and the plastic films coated with the fluorocarbon coatings were then mounted in outdoor racks on the roof of Springborn Laboratories' facilities in Enfield, Connecticut. Evaluation was performed monthly and a record of rainfall was kept to corre? ate soiling effects with precipitation. The surfaces of these test specimens were not washed or touched with the hands.

The degree of soiling on the test specimens was monitored iy measurement of the $F$ rcentage of decrease in the short-circuit current (Isc) output of a standard silicon solar cell positioned behind the soiled test specimens, as described above for the JPL soiling studies.

Table 2 records the percentage of reduction in $I_{s c}$ for all of the test specimens over 28 months of continuous outdoor exposure (Reference 18). For Tedlar, the best coating is found to be E-3820, and Figure 7 compares the soiling behavior of uncoated Tedlar (control) and E-3820-coated Tedlar. For Acrylar, the best coating is found to be E-3820 in combination with ozone, and Figure 8 compares the soiling behavior of uncoated Acrylar (control) and the E-3820-ozone-coated Acrylar specimen. For glass, little difference is noted in comparing E-3820 and L-1668, but E-3820 wight be slightly better (Figure 9).

Comparing the uncoated controls, glass has ill least tendency to retain natural soil, followed by Tedlar and then Acrylar, buth having greater tendencies to retain natural soil. This difference in soiling behavior between glass and plastic films had been observed earlier (References 8 and 9). However, with the fluorocarbon antisoiling coatings, the soiling behavior of all three materials becomes essentially the same. Thus soiling-related optical losses of glass superstrate designs and substrate designs with plastic film outer covers will be essentially the same. 
Table 2. Experimental Evaluation of Fluorocarbon Antisoilirg Coatings, Monitored by Measurements of Percentage of Reduction in Solar-Cell Short-Circuit ( $I_{s c}$ ) From Accumulation of Natural

Surface Soiling (Reference 18)

\begin{tabular}{|c|c|c|c|c|c|c|c|c|c|c|c|c|c|c|c|c|c|c|c|c|c|c|c|c|c|c|c|c|}
\hline \multirow[b]{2}{*}{ Materials } & \multirow[b]{2}{*}{1} & \multirow[b]{2}{*}{2} & \multirow[b]{2}{*}{3} & \multirow[b]{2}{*}{4} & \multirow[b]{2}{*}{5} & \multirow[b]{2}{*}{6} & \multirow[b]{2}{*}{$\cdot$} & \multirow[b]{2}{*}{8} & \multirow[b]{2}{*}{9} & \multirow[b]{2}{*}{10} & \multirow[b]{2}{*}{11} & \multirow[b]{2}{*}{12} & \multicolumn{3}{|c|}{ MONTHS } & \multirow[b]{2}{*}{16} & \multirow[b]{2}{*}{17} & \multirow[b]{2}{*}{18} & \multirow[b]{2}{*}{19} & \multirow[b]{2}{*}{20} & \multirow[b]{2}{*}{21} & \multirow[b]{2}{*}{22} & \multirow[b]{2}{*}{23} & \multirow[b]{2}{*}{24} & \multirow[b]{2}{*}{25} & \multirow[b]{2}{*}{26} & \multirow[b]{2}{*}{27} & \\
\hline & & & & & & & & & & & & & 13 & 14 & 15 & & & & & & & & & & & & & 28 \\
\hline Sunadex Glass & & & & & & & & & & & & & & & & & & & & & & & & & & & & \\
\hline Control & 1.5 & 2.0 & 1.9 & 1.7 & 3.0 & 2.8 & 2.3 & 2.9 & 4.7 & 3.2 & 2.0 & 3.1 & 3.8 & 2.3 & 1.9 & 2.4 & 2.5 & 1.7 & 4.0 & 3.7 & 2.2 & 2.0 & 3.2 & 3.4 & 2.8 & 2.9 & 2.9 & 2.0 \\
\hline$L-1668$ & 0.0 & 1.2 & 1.3 & 0.3 & 0.4 & 0.4 & 1.0 & 1.0 & 4.3 & 2.3 & 1.0 & 1.0 & 1.5 & 1.0 & 2.1 & 3.0 & 2.0 & 1.7 & 3.3 & 3.0 & 0.0 & 2.9 & 2.1 & 3.6 & 1.9 & 1.9 & 0.9 & 2.0 \\
\hline$\varepsilon-3920$ & 0.1 & 0.1 & 2.2 & 1.2 & 1.5 & 1.2 & 2.3 & 2.0 & 3.8 & 2.7 & 0.6 & 1.3 & 1.7 & 0.8 & 1.6 & 1.6 & 1.5 & 1.1 & 2.6 & 2.0 & 0.0 & 0.5 & 2.3 & 3.6 & 1.5 & 1.6 & 0.5 & 1.0 \\
\hline Tedlar $100 \mathrm{BG} 30 \mathrm{U}$ & & & & & & & & & & & & & & & & & & & & & & & & & & & & \\
\hline Control & 2.4 & 3.3 & 1.0 & 3.5 & 4.7 & 4.7 & 5.1 & 6.3 & 7.7 & 8.8 & 6.7 & 6.5 & 5.8 & 4.5 & 5.0 & 4.9 & 4.6 & 5.8 & 6.3 & 6.2 & 5.0 & 4.1 & 7.4 & 7.4 & 5.8 & 5.3 & 5.1 & 5.9 \\
\hline$L-1668$ & 1.5 & 1.5 & 2.7 & 1.8 & 3.8 & 2.9 & 3.5 & 3.7 & 6.0 & 5.3 & 3.9 & 4.2 & 5.3 & 4.6 & 5.3 & 5.0 & 4.9 & 5.4 & 6.0 & 6.0 & 4.4 & 4.9 & 5.4 & 6.7 & 5.4 & 0 & 4.9 & 3.7 \\
\hline L-1668/0zone & 0.7 & 0.9 & 2.1 & 2.2 & 2.8 & 3.1 & 3.5 & 3.4 & 5.9 & 5.0 & 3.7 & 4.8 & 5.1 & 4.4 & 5.0 & 5.4 & 5.7 & 5.2 & 5.1 & 5.1 & 2.3 & 4.4 & 6.0 & 7.1 & 6.1 & - & 4.6 & 4.0 \\
\hline$E-3820$ & 0.0 & $0 . c$ & 3.5 & 0.8 & 1.5 & 1.7 & 0.9 & 1.3 & 2.4 & 3.8 & 2.1 & 2.4 & 2.3 & 2.3 & 1.7 & 1.8 & 1.6 & 1.7 & 2.3 & 2.8 & 0.0 & $c .9$ & 0.4 & 3.1 & 2.8 & 0.7 & 1.0 & 1.6 \\
\hline E-3820/0zone & 3.2 & 2.9 & 0.0 & 2.4 & 3.9 & 3.7 & 4 & 4.4 & 5.8 & 6.4 & 3.9 & 4.1 & 4.4 & 3.2 & 5.5 & 5.8 & 6.5 & 5.8 & 5.6 & 6.3 & 4.3 & 4.1 & 6.6 & 7.1 & 5.5 & 5.9 & 4.6 & 3.7 \\
\hline Acrylar X-22417 & & & & & & & & & & & & & & & & & & & & & & & & & & & & \\
\hline Control & 3.1 & 3.9 & 4.4 & 3.7 & $\ldots 1$ & 5.4 & 6.4 & 7.51 & 10.2 & 10.8 & 7.9 & 1.8 & 8.1 & 6.4 & 7.2 & 7.6 & 7.2 & 7.3 & 9.4 & 9.8 & 6.2 & 7.3 & 8.2 & 9.3 & s.i & 7.8 & 6.4 & 8.1 \\
\hline$L-1668$ & 0.8 & 0.4 & 1.8 & 2.1 & 3.5 & 3.5 & 5.0 & 3.9 & 5.1 & 66 & 5.6 & 5.0 & 49 & 3.2 & 4.6 & 5. & 4.7 & 4.7 & 6.4 & 6.2 & 0.9 & 2.6 & 5.3 & 6.4 & 4.6 & 5.2 & 5.3 & 4.3 \\
\hline L-1668/Gzone & 2.9 & 2.5 & 2.8 & 2.5 & 3.4 & 3.2 & 4.5 & 5.0 & 6.3 & 6.1 & 4.5 & 4.6 & 6.1 & 5.3 & 4.8 & 5.5 & 5.6 & 5.3 & 7.5 & 6.7 & 2.8 & 5.5 & 0.5 & 8.0 & 0.3 & 7.6 & S.R & 5.4 \\
\hline$E-3320$ & 1.5 & 1.6 & 2.4 & 2.3 & 2.8 & 2.6 & 3.9 & 3.9 & 6.7 & 6.8 & 4.4 & 5.4 & 6.0 & 4.2 & 5.0 & 4.0 & 3.6 & 5.5 & 6.0 & 5.7 & 1.3 & 4.3 & 4.6 & 7.1 & 6.4 & 5.6 & 5.7 & 5.7 \\
\hline E-3820/Ozone & 0.8 & 2.0 & 2.3 & 1.8 & 2.5 & 3.1 & 4.0 & 3.2 & 5.0 & 4.9 & 3.2 & 4.0 & 4.9 & 3.8 & 1.0 & 2.1 & 1.4 & 1.0 & 2.6 & 3.4 & 0.0 & 2.0 & 1.9 & 3.9 & 1.8 & 1.8 & 1.5 & 1.9 \\
\hline
\end{tabular}




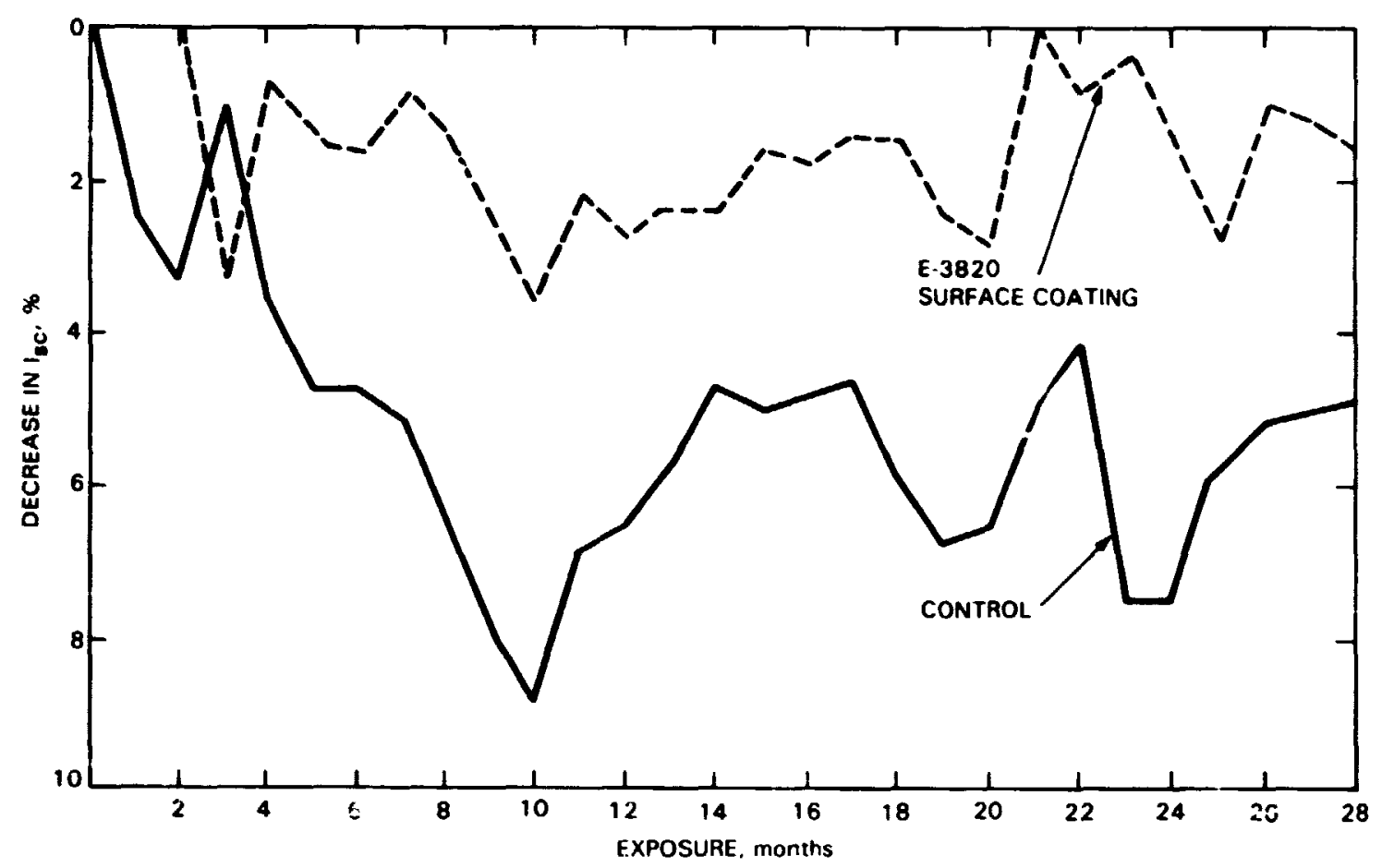

Figure 7. Outdoor Soiling Behavior of Tedlar 100BG30UT Plastic Film, With and Without a Fluorocarbon Antisoiling Coating

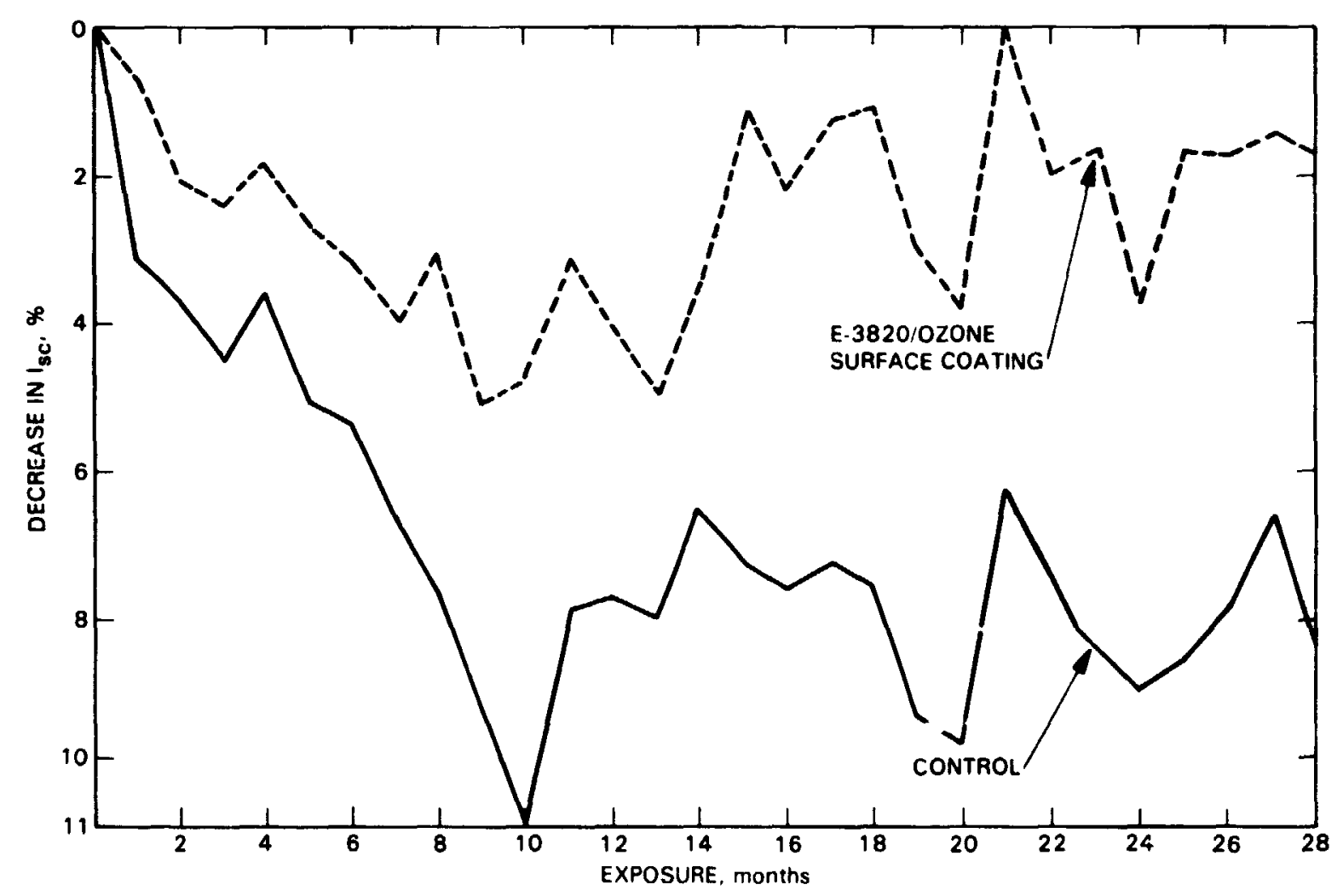

Figure 8. Outdoor Solling Behavior nf Arrylar X-22417 Plastic Film, With and Without ${ }^{*} \quad$ be antisoiling Costing 


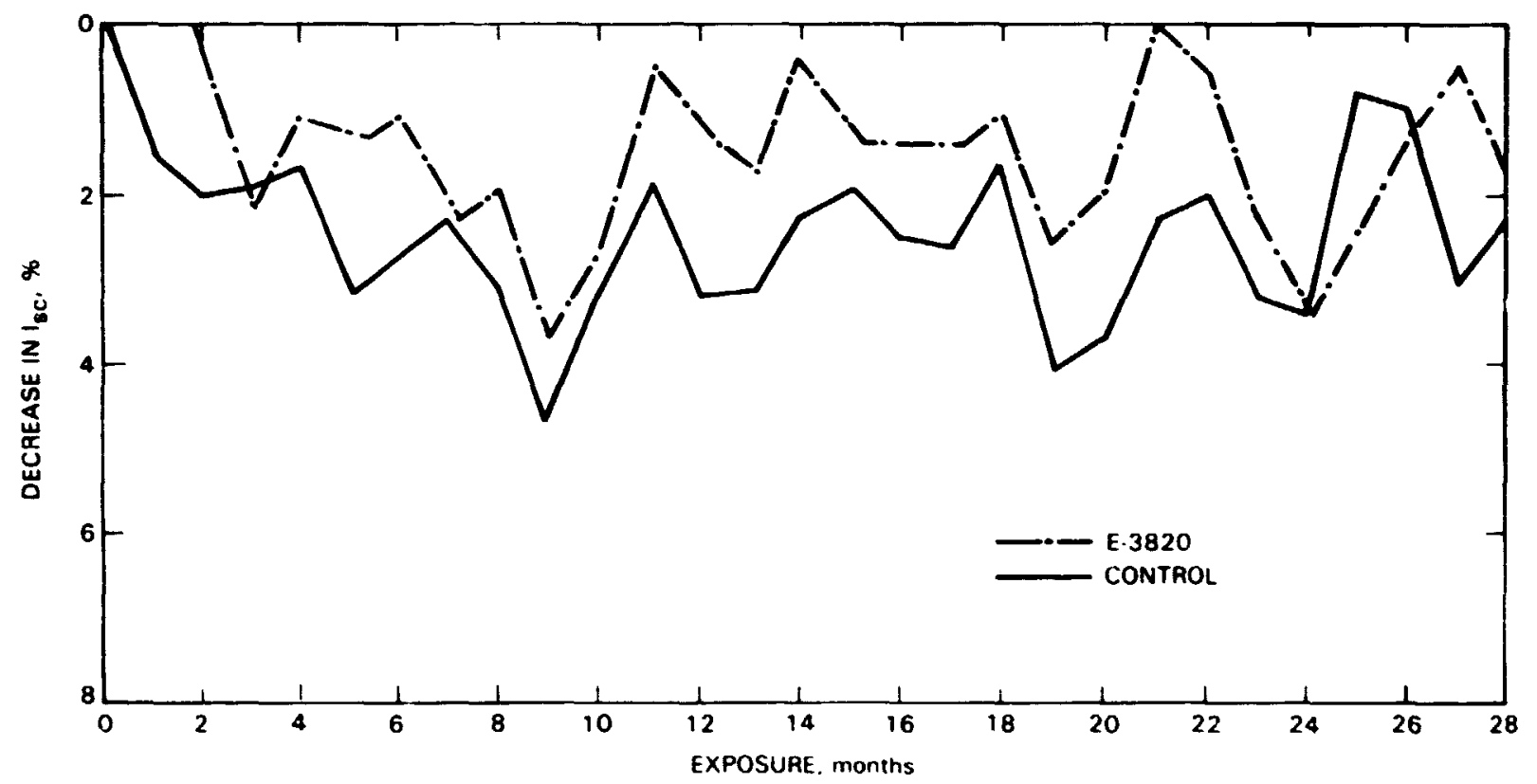

Figure 9. Outdoor Soiling Behavior of Glass With and without a Fluorocarbon Antisoiling Coating

Figure 10 is a plot of the rainfall pattern in Enfield, Connecticut, over the soiling exposure period. The data are plotted as monthly rainfall totals in inches versus the month in which the rainfall occurred. The highs and lows in the rainfall totals generally correlate with the soiling highs and lows shown in Figures 7, 8 and 9. A sustained dry period with little rain occurred during the fourth to the loth month, with no rain at all in the eighth and ninth months. This resulted in the maximum accumulation of surface soiling observed from all test specimens over the entire outdoor exposure period. After the ninth and 10th months, rainfall began to increase, and the surfaces became cleaner.

Over this exposure period, the monthly rainfall totals were accumulated from a fair number of rainstorms distributed throughout the month. In the 21 st month, however, an especially intense and heavy rainstorm of several cays' duration accounted for almost all of the monthly total. As shown in Figures 7,8 and 9 , this intense rainstorm removed virtually all of the measurable soil from the fluorocarbon-coated surfaces.

Inspection of the fluorocarbon-coated-surface data curves in Figures 7 , 8 and 9 suggest that little, if any at all, of a rain-resistant soil base had formed on these surfaces, whereas inspection of the control data curves in the same figures reveals the formation of a rain-resistant soil base on each of the three materials. 
MONTHS

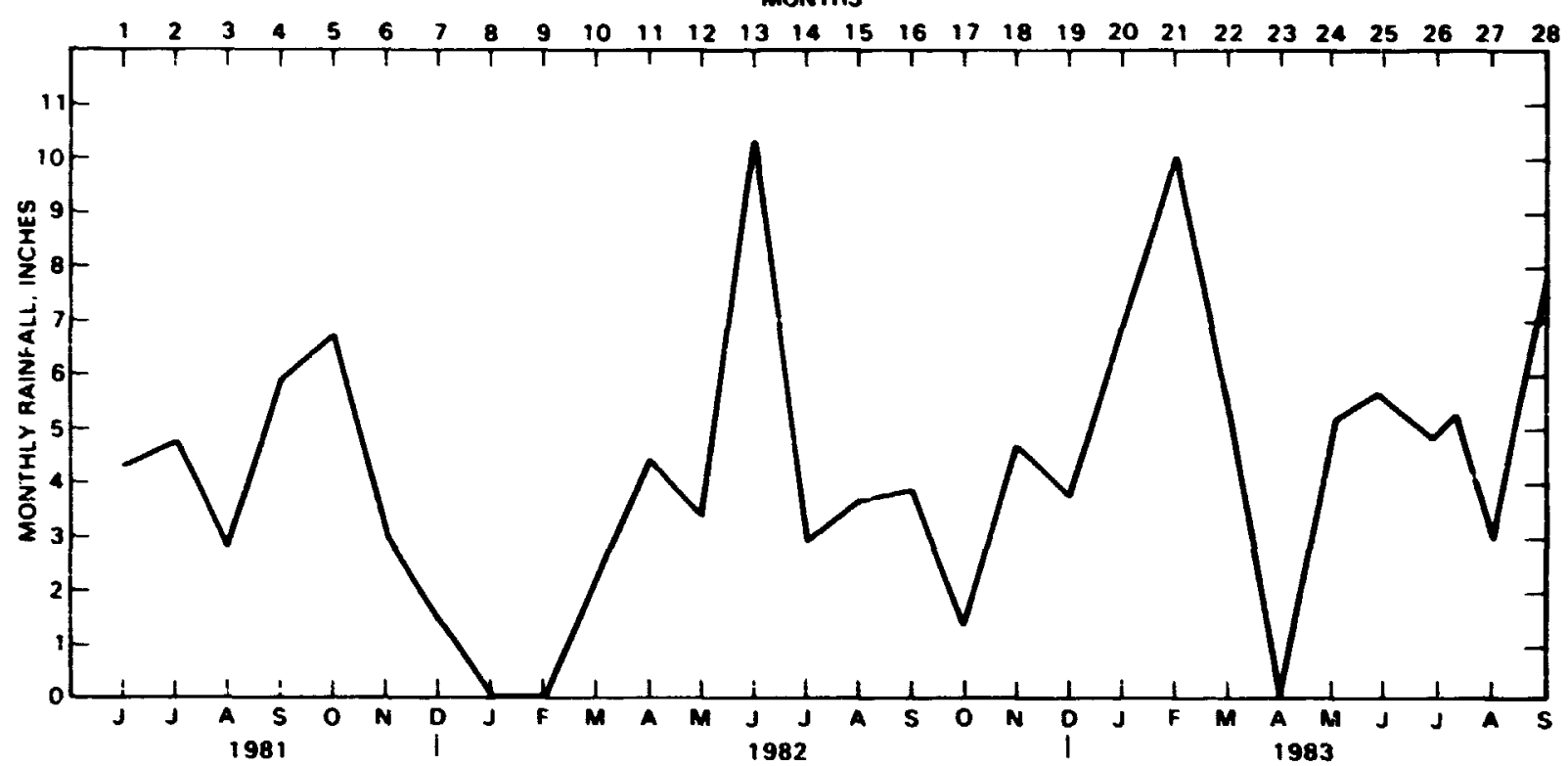

Figure 10. Rainfall in Enfield, Connecticut, Over a 28-Honth Period

The data in Table 2 were averaged over the 28 month period, and the time-averaged values are given in Table 3 . The glass control sample realized an average optical loss of about $2.65 \%$ over the 28 -month period, whereas the Tedlar control realized an average loss of about 5.387 and the Acrylar control specimen realized an average loss of about $7.20 \%$. Soiling data measured on similar materials in Pasadena (Table 1), showed about 37 loss for glass, 37 loss for Tedlar, and $5 \%$ loss for Rorad acrylic film, which is similar in chemistry to Acrylar.

The data in Table 3 also reveal more clearly that the better-performing fluorocarbon coating for all three materials is E-3820. On glass, the E-3820 coating resulted in a reduction of coiling-related optical losses from $2.65 \%$ to 1.55\%, for an average performance gain of nearly $1.1 \%$. Similarly, on Tedlar, the E-3820 results in an improvement from 5.387 to $1.70 z$ for an average performance gain of nearly $3.68 \%$, and Acrylar realized an average performance gain of nearly 4.51z. These performance gains can be economically important to the electrical power output of a photovoltaic module.

With respect to Layer $C$ behavior, if it can be assumed that no rain-resistant layers ( $A$ or $B$ ) formed on the E-3820 coated glass specimen, then the time-average value of $1.55 \%$ (Table 3 ) can be considered as the time-average optical loss associated with the cyclical deposition and rain removal of layer $C$ soil, in Enfield, Connecticut. The higher minimums observed for Tedlar and Acrylar, respectively $1.70 \pi$ and $2.59 \%$, may reflect the formation of some lower layers that resist removal by gentle rainfall, but not intense rainfall as occurred in the $21 s t$ month of outdoor exposure. This suggests possibilities for further performance gains from the use $0:$ improved fluorocarbon coating materials, which is the subject of ongoing FSA research activity. 
Table 3. Tine-Averaged Values of the 28-Honth Soiling

Data Given in Table 2

Glass

Control

with E-3820

with $\mathrm{L}-1668$

\section{Tedlar}

Control

with E-3820

with L-1668/ozone

with $\mathrm{L}-1668$

with E-3820/ozone

Acrylar

Control

with E-3820/ozone

with $\mathrm{L}-1668$

with E-3820

with L-1668/ozone
5.38

2.65

1.55

1.59

1.70

4.28

4.43

4.68

7.20

2.59

4.21

4.44

5.15

In conclusion, low-surface-energy treatments based on fluorosilane chemistry appear to be effective in retarding the accumulation of dirt on the candidate outer surfaces of interest. The most effective soil retardant treatments identified to date are: for Sunadex glass, E-3820; for Acrylar, ozone activation followed by E-3820; and for Tedlar, treatment with E-3820.

After 28 months of outdoor exposure, the E-3820 treatments resulted in performance gains from nearly $1 \%$ for glass to $4 \%$ for Acrylar in light throughput measured with a standard ce?l and light source. The removal of accumulated soil correlated well with rainfall but not with precipitation as snowfall. These 28 months of experimental effort provideo support for the theoretically derived considerations for low-soiling coatings, and a rationale for future activities for improvements in fluorocarbon cuating chemistry, as well as cor siderations relative to minimizing the effects of layer $C$. Experimental evidence suggests that layer $C$ is site-dependent, rain-frequencydependent, and possibly tilt-dependent. Minimization of layer $C$, by either understanding its natural properties or by maintenance, awaits a better understanding. 



\section{SEr.TIOA V}

\section{SURTARY}

Essential findings and conclusions can be sumarized as follows:

(1) All surfaces exposed outdoors appear to be susceptible to soil accumation; annitude is both site-dependent and aterialdependent.

(2) Soil accumlation appears to involve up to three distinct layers, wich we designate as:

Layer A: A soil :aq̣a inediately on the surface of the exposed material that is tenaciousif attached, resistant to removal by rain, and requires extremely abra-..ve cleaning techniques for its resroval.

Layer B: A less tenacious soil layer that can form on layer A or on the natural surface if no layer $A$ has forned. This layer is also resistant to rewoval by rain, but is easily removed by comon cleaning techniques, such as washing with soap and water solution.

Layer C: A third soil layer that can form on layer $B$ or on the natural surface if no layer $A$ and layer $B$ have

formed. This soil layer is readily rewoved by rain.

(3) Rain is the nost effective enviromental agent for nutural cleaning of layer $C$. All other environmental agents, such as wind and snow, have minias or negligible natural cleaning qualities.

(4) The characteristics of surfaces having the wost resistance to formation of layers $A$ and $B$ appear to be:

(a) Hardness

(b) Swoothness

(c) Hydropłobicity

(d) Low surface energy

(e) Nonstickiness (chemically clean of sticky materials, surface and bu1k)

(f) Cleanliness (chemically clean of water-soluble salts and first-period elements, surface bulk)

(8) Weathering stability (resistance to UV-photooxidation and/or hydrolysis) 
(5) Low-surface-energy fluorocarbon compounds chemically attached to glass and polyeer surfaces are being found to result in significant reductions in the quantity of retained soil on the surfaces of those materials. 
1. Cuddihy, E.F., "Theoretical Considerations of Soil Retention," Solar Energy Materials, Vol. 3, pp. 21-33, 1980.

2. Ross, D.L., "Coatings for Video Discs," RCA Review, 39, p. 136 (1978).

3. Moser, B.G., and Landel, R.F., "A Theory of Particle-Particle Interaction Describing the Mechanical Properties of Dental Amalgam," JPL SPS No. 37-40, Vol. IV, p. 84 (1966).

4. Schneider, H., Mechanical Removal of Spacecraft Microbial Burden," Subtask I of Spacecraft Cleaning and Decontamination Techniques, Chapter 6 of Planetary Quarantine, Annual Review, Space Technology and Research, JPL TR-900-597, Jet Propulsion Laboratory, Pasadena, California, February 1973.

5.

Sheratte, M.B., "Cleaning Agents and Techniques for Concentrating Solar Collectors," Final Report, No. MDCG 8131, McDonne11-Douglas Astronautics Co. West, September, 1979.

6.

Adams, P.B., "Glass Containers for Ultrapure Solutions," Chapter 14 in Ultrapurity, Marcel Dekker, Inc., 1972.

7.

Porter, M.C., "Membrane Filtration," Section 2.1 in Handbook of Separation, McGraw-Hill, New York, P. 2-3 (1979).

8. Hoffman, A.R., and Maag, C.R., "Airborne Particulate Soiling of Terrestial Photovoltaic Modules and Cover Materials," in Proceedings of the Institute of Environmental Sciences, Philadelphia, Pennsylvania, May 11-14, 1980, Institute of Environmental Sciences, Mount Prospect, IIlinois, 1980.

9.

Hoffman, A.R., and Maag, C.R., Photovoltaic Module Soiling Studies, Mav 1978 to October 1980, JPL Document No. 5101-131, JPL Publication 80-87, DOE/JPL-1012-49, Jet Propulsion Laboratory, Pasadena, California, November 1, 1980.

10.

Freese, J.M., "Effects of Outdoor Exposure on the Solar Reflectance Properties of Silvered Glass Mirrors," Sandia National Laboratories Report 78-1649, September 20, 1978.

11. Willis, P.B. and Baum, B., "Investigation of Test Methods, Material Properties, and Processes for Solar Cell Encapsulants," Annual Report, Springborn Laboratories, Inc., Enfield, Conn., DOE/JPL Document No. 954527-82/23, Jet Propulsion Laboratory, Pasadena, California, July, 1982.

12. Roth, E.P. and Anaya, A.J., "The Effect of Natural Cleaning on the Size Distribution of Particles Deposited on Silvered Glass Mirrors," paper presented at the Second Solar Reflective Materials 
Workship, sponsored by the Department of Energy; M.A. Lind, Battelle Pacific Northwest Laboratories, Chairman; San Francisco, California, February 12-14, 1980.

13. Draft, R.G., Mell, R.J., and Segers, E.C., "Investigatior, of Soiling Characteristics of Polymeric Film," IIT Research Institute, Chicago, Illinois, Final Report No. LS-72-7451 inr the Jet Propulsion Laboratory, February, 1982.

14. Patrick, R.L., "The Effect of Water on the Adhesive Bond," Lecture presented at a Symposium on Adhesion Principles and Practice, Rent State University, June, 1980.

15. Gupta, A., "Effect of Photodegradation on Chemical Structure and Surface Characteristics of Silicone Pottants Used in Solar Cell Modules," JPL Internal Document 5101-79, Jet Propulsion Laboratory, Pasadena, California, August 18, 1978.

16. Anderson, S., Tandon, D., Kohlenberger, L.B., and Blair, F.G., J. Am. Cer. Soc., 521 (1969).

17. Cuddihy, E.F., et al., Photovoltaic Module Encapsulation Design and Materials Selection: Volume I, JPL Document No. 5101-177, JPL Publication 81-102, DOE/JPL-1012-60, Jet Propulsion Laboratory, Pasadena, California, June 1, 1982.

18. Willis, P.B., "Investigation of Test Methods, Material Properties, and Processes for Solar Cell Encapsulants," Seventh Annual Report, Springborn Groups, Inc., Enfield, Conn., DOE/JPL Document No. 954527-83/24, Jet Propulsion Laboratory, Pasadena, California, 1983. 